\title{
POTENCIALIZAÇÃO DA EFICIÊNCIA DAS EQUIPES K-SAR ATRAVÉS DE PRÁTICAS NUTRICIONAIS E CONDICIONAMENTO FÍSICO CANINO: UMA ANÁLISE DA LITERATURA
}

\author{
Luciano Warth Silva Rangel ${ }^{1}$ \\ Walter Parizotto ${ }^{2}$
}

\begin{abstract}
RESUMO
O presente trabalho se refere a uma pesquisa bibliográfica que tem por objetivo: buscar norteadores para as práticas nutricionais e físicas aplicadas aos cães de busca, resgate e salvamento. Para realização da pesquisa foi buscado nas plataformas de pesquisa on-line: Biblioteca CBMSC, Scielo e Google Acadêmico, trabalhos acadêmicos sobre cães, cães de resgate e suplementação de cães. Ao analisar os trabalhos, como resultados, chegou-se à conclusão que as literaturas existentes são insuficientes para embasar o conhecimento científico do bombeiro militar que atua na função de condutor na atividade de busca, resgate e salvamento com cães.
\end{abstract}

Palavras-chave: Cães de Busca e resgate. Condicionamento físico canino. Nutrição canina.

\footnotetext{
${ }^{1}$ Graduado em Processos Gerenciais pela UNIASSELVI, 2012. Cinotécnico do Corpo de Bombeiros Militar de Santa Catarina. E-mail: rangel@cbm.sc.gov.br / warthrangel@gmail.com.

${ }^{2}$ Tenente-Coronel do Corpo de Bombeiros Militar de Santa Catarina. Mestre em Engenharia Florestal. Email: parizotto@cbm.sc.gov.br
} 


\title{
ENHANCEMENT OF THE EFFICIENCY ON K-SAR TEAMS THROUGH NUTRICIONAL PRACTICES AND CANINE PHYSICAL CONDITIONING: AN ANALYSIS REVIEW
}

\begin{abstract}
The actual work refers to a bibliographic review that aims to: looking for guides to nutritional and physical practices applied to search dogs, rescue and saving. In order to make the research we've look for on the on-line search platforms: CBMSC Library, Scielo and Academic Google, academic works about dogs, rescue-dogs and dogs' supplementation. Once the works have been done, as results, we've reached the conclusion that the actual literature isn't sufficient to base the scientific knowledge of the military fireman who acts in the role of handler during the search, rescue and salvation activity with dogs.
\end{abstract}

Keywords: Search and Rescue Dogs. Canine Physical Conditioning. Canine Nutrition. 


\section{INTRODUÇÃO}

As instituições militares são marcadas pela padronização das ações, procedimentos e, especialmente, pelo comprometimento com a causa que estão envolvidas, e ainda, com a sua atividade fim. Uma das especialidades do CBMSC é o serviço cinotécnico, que teve atuações em eventos catastróficos de repercussão nacional, como o rompimento da barragem I no complexo de minas do Córrego do Feijão e a barragem de fundão no distrito de Bento Rodrigues em Mariana, todas no estado de Minas Gerais. Nos Corpos de Bombeiros Militares, os cães são utilizados como ferramentas de trabalho que potencializam a eficiência das equipes frente a uma ocorrência de busca e resgate de pessoas desaparecidas, sejam elas em mata ou escombro. Segundo Prestes (2009), a utilização de cães para resgate iniciou na Segunda Guerra, quando pilotos ingleses, ao realizarem incursões em territórios ocupados pelos alemães, eram abatidos sobre o canal da mancha, onde sentiu-se a necessidade de criar um sistema de busca e salvamento destes pilotos. Cortez Trujillo (2002) apud Prestes (2009) ainda cita que após os bombardeios sobre a cidade de Londres, as guarnições de Bombeiros utilizaram cães da raça Dálmata para localizar e resgatar vítimas sob os escombros gerados pelos ataques.

Comparando a necessidade humana e a necessidade dos cães - dadas as proporções - é possível comparar um cão de busca, resgate e salvamento, com um jogador de futebol. Os jogadores de futebol passam grande parte dos seus dias realizando atividades recreativas e atividades que os capacitam para atuar durante a partida com maior eficiência, por exemplo: treinos de cobrança de faltas, cabeceio, musculação, alimentação regrada, entre outros. Com cães, respeitando a individualidade de cada animal, isso não é diferente. Os cães têm a necessidade de praticar atividades lúdicas que trabalhem o seu cognitivo direcionado para busca, alimentação balanceada e treinos de atividade física. Além das diferentes características existentes entre as diversas raças, deve-se 
levar em conta os níveis de atividade física, clima, idade, sexo, composição corporal e outros fatores que possam influenciar a quantidade de alimento ingerido (CASE, CAREY e HIRAKAWA, 1998).

Sobre a aprendizagem e comunicação, para Skinner apud Parizotto (2019) a aprendizagem é a aquisição de novos comportamentos. Já Parizotto (2019, p. 30), no seu livro "A Arte de Ensinar seu Cachorro", relaciona, por meio de exemplos práticos, a impaciência do ser humano para ensinar seus cães: "Seres humanos esperam dois anos para seus bebês deixarem de usar fraldas, mas terão dificuldade de esperar 3 meses para que 0 bebê cachorro aprender a fazer suas necessidades no local correto". Baseado no texto acima, é possível inferir o motivo da discrepância supracitada: condutores passam parte de suas vidas operativas focados em aprender princípios de etologia e psicologia canina, processos de aprendizagem e comunicação, figuração, noções de busca terrestre, deslizamento e restos mortais; contudo, muitos acabam não se atentando ao processo - o condicionamento físico - que, quando deficiente, não explora ao máximo o potencial do cão. Isso pode acontecer por conta de os cães possuírem alto nível de energia e, em função disso não demonstrarem, de forma explícita, o seu preparo físico.

Para tanto, este artigo foi desenvolvido levando em consideração as informações supracitadas, o fato de o serviço cinotécnico ${ }^{3}$ ser um dos recursos especializados do Corpo de Bombeiros Militar de Santa Catarina (CBMSC) em âmbito estadual, nacional, com reconhecimento internacional. que durante operações, certificações, cursos ou até mesmo em treinamentos, a discrepância no condicionamento físico de alguns cães - entre o plantel do CBMSC e o de outros estados - que são empenhados em atividade de busca e resgate é visível por todos, e que, conforme Eberle et al (2019) relata, os cães são essenciais para encontrar vítimas atingidas por desastres de origem

\footnotetext{
${ }^{3}$ Serviço de cinotecnia: Busca, resgate e salvamento com cães.
} 
natural, que quanto mais rápida for a sua busca, maior será a sua chance de salvá-la.

O objetivo deste trabalho é: buscar norteadores para as práticas nutricionais e físicas aplicadas aos cães de busca, resgate e salvamento. Um cão sadio, que atenda às condições sanitárias exigidas pela câmara técnica de veterinária da Coordenadoria do Serviço de Busca com Cães através da diretriz operacional no 10/2020 CBMSC, não terá dificuldades em executar práticas a ele designadas e potencializará a eficiência das equipes $K$-Sar ${ }^{4}$ dentro da operação de desastre. Para tanto, nortear o conhecimento empírico analítico do autor com técnicas aplicadas no cão Orion $^{5}$, baseado no condicionamento aplicado para cães de trenó adaptado para as necessidades e realidades presentes no estado e instituição catarinenses, é a inspiração desse trabalho.

Observa-se, primeiramente, que, no contexto da padronização ora existente nas instituições militares, já se encontram consagrados os procedimentos para treinamentos em atendimento pré-hospitalar, combate a incêndios e demais campos de atuação dos Corpos de Bombeiros, de forma geral. Porém, não há volume substancial de literatura que discorra sobre condicionamento físico de cães de busca, resgate e salvamento, necessário à evolução das instituições, motivo pelo qual o presente artigo fora criado.

\section{MÉTOdOS DE FORMAÇÃo DE CÃES E SITUAÇÕES DE BUSCA}

Parizotto (2018), conceitua o cão como uma ferramenta de trabalho, que como todas as outras existentes vêm com um manual. Para tanto, o autor cita, em seu Manual do Curso de Formação de Bombeiro Cinotécnico do Corpo de Bombeiros Militar de Santa Catarina, na lição zero um, algumas atitudes que o condutor de um cão de resgate deve possuir para entender e condicionar o seu

\footnotetext{
${ }^{4}$ Kanine Search and Rescue.

${ }^{5}$ Orion Wolf Pansy Lab: Cão certificado do CBMSC. Raça Labrador Retriver. Lotado no $5^{\circ}$ Batalhão de Bombeiros Militar, com sede em Lages. Tem como condutor Soldado Rangel. RG RG/SPAI/19/03837 CHIP: 900005761120515.
} 
cão - até então um joia bruta - para ser lapidado a ser um cão de resgate. Esse cão após submetido a prova de certificação, será empenhado em ocorrências reais, os quais serão citados abaixo. É importante frisar que para obtenção de certificação, essa dupla de homem e cão, chamada de binômio, será submetida a onze etapas que antecedem o início de sua vida operativa no Corpo de Bombeiros Militar de Santa Catarina. São elas: a) seleção e formação do cinotécnico; b) seleção do filhote; c) desenvolvimento dos instintos naturais; d) auto-figuração; e) figuração; f) universalização dos espaços; g) universalização do figurante; h) ; i) reforço; j) certificação; k) manutenção e recertificação.

Na primeira etapa, a de seleção e formação do cinotécnico, inicia-se o processo de formação do binômio. O militar escolhido deve possuir afinidade com a função bem como deve estar habilitado para 0 atendimento de ocorrências rotineiras da sua região. $O$ bombeiro que comporá esse binômio necessita dos seguintes cursos: busca e resgate em estruturas colapsadas e busca terrestre e sistema de comando de operações, além de cumprir 300 horas de estágio supervisionado com binômio certificado.

A segunda etapa, que se refere à seleção do filhote, ressalta que o perfil do cão para busca deve ser selecionado na mais tenra idade. Os traços familiares, psicológicos e familiares facilitarão o condicionamento do cão de busca. Filhotes que possuem boa herança genética, facilitam em $20 \%$ (vinte por cento) a carga de trabalho do seu condutor.

$\mathrm{Na}$ fase número três, sobre o desenvolvimento de instintos naturais (imprinting) é uma fase extremamente importante no condicionamento do cão de busca, resgate e salvamento. Esta fase inicia na segunda semana de vida do cão e se estende até a décima segunda. A partir da terceira semana de vida, o cão começa a interagir com as pessoas e deixa de ser sonolento. Brincadeiras estimulando a caça e o lado lúdico do cão são essenciais para que ele tenha paixão ou compulsão pela brincadeira.

$\mathrm{Na}$ etapa de auto-figuração, o cão deixa a matilha e passa a conviver de maneira mais próxima ao seu condutor, onde usará o seu latido 
para requerer a brincadeira, latidos estes, que no futuro salvarão uma vida em perigo. Nesse momento, o cão passará a realizar suas primeiras buscas, onde aprenderá a procurar pessoas, nesse caso, a pessoa com a qual possui maior vínculo: seu condutor.

Na quinta etapa, a de Figuração, o cão passará a procurar outra pessoa que não seja o seu condutor. Nessa fase, espera-se que o figurante traga alegria a esse novo momento na vida do cãozinho. O figurante forjará o caráter desse cão e poderá ou não torná-lo ainda mais compulsivo pela brincadeira, tudo depende do seu dinamismo e ludicidade que conduz o treinamento do referido cão.

A etapa de Universalização dos espaços, é o momento em que é apresentado ao cão o maior número de ambientes possíveis. Nessa fase, o cão deve se mostrar receptivo a conhecer novos locais, bem como resolver os problemas que the forem impostos nesses novos ambientes.

$\mathrm{Na}$ sétima etapa, a Universalização do figurante, o cão se torna ainda mais compulsivo pela brincadeira com o ser humano e não fica "preso". Somente a brincadeira com duas pessoas em específico (o condutor e o figurante), é o momento em que ele descobre que brincar com todo e qualquer ser humano após uma busca é prazeroso. Orienta-se para que os condutores, nesta fase, realizem o exercício colombiano conhecido como Estrela K-Sar ${ }^{6}$.

$\mathrm{Na}$ etapa número oito, o condutor foca o condicionamento do seu cão na área de atuação que achar atinente. Pode se especializar em diversas áreas de atuação do know-how bombeiro militar.

$\mathrm{Na}$ fase de Reforço, obediência e correção, o condutor oportuniza ao seu cão um novo modelo de aprendizado, que não seja diretamente direcionado à busca. Nessa fase, o cão aprenderá comandos para percorrer locais instáveis, acima do nível do solo, abaixo do nível do solo e, com isso, minimizará a chance de deixar uma vítima para trás. Nessa fase o condutor

\footnotetext{
${ }^{6}$ Exercício onde cinco figurantes formam uma estrela e o condutor direciona o cão para indicar essas vítimas.
} 
também deverá proporcionar momentos de lazer ao cão, para que ele execute essas tarefas bem como as de busca com maior prazer e tranquilidade.

A Certificação, décima etapa, é o momento em que o condutor e o cão colocam em prática, sob supervisão de uma pessoa habilitada, o árbitro, suas capacidades operativas desenvolvidas durante todo esse treinamento - cerca de um ano e meio. Diversos fatores são observados em uma prova de certificação e aos olhos do gestor, possuir um cão certificado em uma operação de desastre é a garantia de que o cão cumpre aquilo que está proposto a fazer.

$\mathrm{Na}$ última etapa, a de Manutenção e recertificação, existe a compreensão de que um cão não é uma máquina. Por isso, o meio em que ele está inserido influenciará diretamente em seu comportamento no dia-a-dia. Para que ele mantenha o rendimento obtido em prova de certificação, deverá o seu condutor criar rotinas que o façam lembrar de tudo aquilo que the foi oportunizado durante o seu treinamento. Por essa razão, mesclar treinamentos lúdicos e simulações de operações reais são atitudes essenciais para o bom desempenho desse cão. É importante frisar também que, como previsto no fluxograma de Parizotto (CBMSC, 2018) e por manutenção da operacionalidade do cão, o processo de recertificação deverá ocorrer a cada dois anos conforme a Diretriz no 10 do Serviço de Cães pelo Corpo de Bombeiros Militar de Santa Catarina.

Após percorrerem dez destes onze passos, segundo a Diretriz Operacional no 10/2020/CBMSC que regula o serviço de cães no Corpo de Bombeiros Militar de Santa Catarina, o binômio será operacionalizado e estará apto a atender diversas ocorrências referente a certificação conquistada. Ainda, na Diretriz Operacional, o cão será empregado nas seguintes situações: Busca Rural; Busca Urbana; Buscas de Restos Mortais; Buscas Subaquáticas; Atividades de Assistência; Demonstrações; Certificação; Simulados; e Atividades extraordinárias. Visto o objetivo deste artigo, serão explanadas de maneira sucinta 0 item um e dois, os quais normalmente há o emprego do serviço de cães. 
Onde o serviço de cães possui a maior empregabilidade são os cenários onde há vítima desaparecida/perdida em espaço rural. Dentre as técnicas utilizadas para localização de uma vítima, pode-se citar as mais utilizadas: venteio e rastreio. $O$ rastreio, é a técnica mais utilizada por cães policiais, onde se baseiam na alteração do $\mathrm{PH}$ do solo através do trajeto pela possível vítima. Secundariamente, esta técnica é realizada por equipes bomberis, mas não é tão utilizada devido à dificuldade em localizar a pista a ser seguida, o que pode tornar a técnica ineficiente. O venteio é a técnica utilizada por equipes com cães do Corpo de Bombeiros Militar de Santa Catarina, por conseguir se adaptar às equipes humanas mais facilmente, onde o cão consegue varrer cinquenta metros para cada lado aumentando assim as chances de localização da vítima ora desaparecida/perdida. Um estudo realizado pela equipe do Corpo de Bombeiros Militar de Santa Catarina, na cidade de Xanxerê, apontou que a área percorrida durante uma busca por cães demora menos da metade do tempo do que se fosse percorrida por equipes somente humanas (CBMSC, 2018).

Quanto à busca urbana, pode-se considerar o cão como a ferramenta com menor custo e maior benefício, visto que tecnologias aplicadas em operações de busca e resgate urbano - que consiste em localizar, acessar, resgatar vítimas sob escombros - localizam vítimas através de gemidos e pequenos sussurros das vítimas entre os escombros, e os cães podem localizar essas vítimas por meio de pequenas amostras de sangue nos escombros. Ainda assim, é descrito sobre os tipos de indicação que são realizadas pelas equipes com cães durante o cenário de busca e resgate urbano, que são três: a) indicação direta: Indicação do local exato onde a vítima se encontra e a equipe de intervenção deverá romper/lograr acesso até o ponto onde se encontra a vítima; b) indicação indireta: quando as equipes não conseguem lograr acesso até a localização exata da vítima, mas indicam a área onde a suposta vítima está localizada; e c) eliminação de zona: quando as equipes indicam que não há vítimas na área percorrida pelo binômio - talvez a 
parte mais difícil do trabalho e que exige maior perícia do condutor em afirmar que no espaço ora descartado não ficou nenhuma vida para trás - desta forma as equipes caninas e humanas podem progredir com segurança no terreno colapsado. Para indicação canina conforme foi anteriormente citado, não basta apenas uma "amostra de sangue". O cão poderá indicar através do odor de sangue, mas uma pessoa possui em sua constituição outros componentes no organismo. Quando em deslocamento entre os escombros, esses formam o chamado túnel de odor, o que facilita a indicação canina em caso de uma vítima presa aos escombros. Diversos fatores influenciam para dissipação desses odores em um cenário real, entre eles podemos citar: os fatores ambientais (vento, chuva, horário e temperatura) e a própria disposição dos escombros (CBMSC, 2018).

Como foi supracitado, os fatores ambientais influenciam durante a operação das equipes com cães em um cenário real, nessa ótica é possível correlacionar com análise do autor a diferença da operação quando se dá em período noturno ou diurno. Por influência da temperatura mais alta, as partículas de odores tendem a dissipar mais facilmente, o que indica que o cão provavelmente faça indicação sobre a vítima. Outro fator que implica na indicação do cão é o tipo de colapso ocorrido na edificação, que pode ser visualizado no manual do aluno do Curso de Formação de Busca e Resgate em Estruturas Colapsadas do Corpo de Bombeiros Militar de Santa Catarina (2018). Diferentemente do que ocorre nas operações de Busca Urbana em escombros, em áreas deslizadas não ocorre o túnel de odor, mas sim o cone de odor, que é confeccionado por equipes humanas durante operação de busca, resgate e salvamento. Eventos naturais extremos ocorridos no Estado de Santa Catarina, evidenciaram a necessidade de capacitação das equipes de resposta frente aos desastres ocorridos de origem natural. 


\section{METODOLOGIA}

Para desenvolver essa pesquisa, optou-se por realizar um levantamento de dados em três plataformas, a fim de analisar as pesquisas já feitas com cães de resgate e relacionadas à suplementação de cães. A busca foi feita nas plataformas digitais: Biblioteca CBMSC, Scielo e Google Acadêmico. Todavia, na plataforma Scielo, não foram encontrados artigos com o tema necessário para esta análise. Conforme se pode visualizar na Tabela 1 , foram encontrados os seguintes resultados:

Tabela 1 - Resultados em números sobre as buscas realizadas nas plataformas digitais

\begin{tabular}{c|c|c|c|c|c|c}
\hline & \multicolumn{2}{|c|}{ Cães } & \multicolumn{2}{c|}{ Cães de resgate } & Suplementação para cães \\
\cline { 2 - 7 } & $\begin{array}{c}\text { Encontrado } \\
\mathrm{s}\end{array}$ & Analisados & $\begin{array}{c}\text { Encontrad } \\
\text { os }\end{array}$ & $\begin{array}{c}\text { Analisado } \\
\mathrm{s}\end{array}$ & $\begin{array}{c}\text { Encontrado } \\
\text { s }\end{array}$ & Analisados \\
\hline Biblioteca CBMSC & 13 & 12 & 0 & 0 & 0 & 0 \\
\hline Google Acadêmico & 0 & 0 & 6 & 0 & 1 & 1 \\
\hline
\end{tabular}

Fonte: Dados de pesquisa.

\section{a. BUSCA POR "CÃES" NA BIBLIOTECA CBMSC}

Ao consultar os trabalhos acadêmicos da Biblioteca CBMSC com a palavra de buscar "cães", apareceram 13 resultados (ver Tabela 1). Dos 13, foram para análise 12 trabalhos, por serem dois o mesmo trabalho que se encontrava repetido. Optou-se pela busca somente com a palavra "cães" pois os artigos e monografias relacionados a cães no CBM geralmente se referem a cães de resgate e, para tanto, todos os trabalhos que aparecem na busca foram analisados (ver Quadro 1). 
Revista Científica do Corpo de Bombeiros Militar de Pernambuco

Artigo Publicado no Vol.07 N.20 - Edição Especial 2021 - ISSN 2359-4829

Versão on-line disponível em: http://www.revistaflammae.com

Quadro 1 - Trabalhos acadêmicos encontrados na busca efetuada na Biblioteca digital CBMSC

\begin{tabular}{|c|c|c|}
\hline & Título & Autor(es) \\
\hline 1. & $\begin{array}{l}\text { O emprego de cães para auxílio na detecção de acelerantes } \\
\text { para incêndio }\end{array}$ & $\begin{array}{l}\text { Jihorgenes Luciano Borges/Vanderlei } \\
\text { Vanderlino Vidal }\end{array}$ \\
\hline 2. & $\begin{array}{l}\text { Parâmetros Técnicos para aprendizagem dos cães de Busca, } \\
\text { Resgate e Salvamento }\end{array}$ & Walter Parizotto \\
\hline 3. & $\begin{array}{l}\text { Implementação do serviço de busca, resgate e salvamento } \\
\text { com cães no estado do Alagoas }\end{array}$ & Roberto Wanderley Amorim Júnior \\
\hline 4. & $\begin{array}{l}\text { A importância do uso de cães como ferramenta na busca de } \\
\text { cadáveres humanos em água doce no Estado de Santa } \\
\text { Catarina }\end{array}$ & Victor Shiroma \\
\hline 5. & $\begin{array}{l}\text { Um estudo sobre as possibilidades de uso de cães nas } \\
\text { atividades de salvamento aquático pelo Corpo de Bombeiros } \\
\text { Militar de Santa Catarina }\end{array}$ & Arthur Roberto Vogel Filho \\
\hline 6. & $\begin{array}{l}\text { A Certificação dos Cães de Busca e Resgate do Corpo de } \\
\text { Bombeiros Militar de Santa Catarina }\end{array}$ & Ismael Mateus Piva \\
\hline 7. & $\begin{array}{l}\text { Emprego de cães nas operações de busca em ocorrências de } \\
\text { movimentos gravitacionais de terra }\end{array}$ & Alan Delei Cielusinsky \\
\hline 8. & $\begin{array}{l}\text { Certificação de Cães de Busca, Resgate e Salvamento: } \\
\text { Análise Sobre a Eficácia da Metodologia de Avaliação } \\
\text { Adotada pelo Corpo de Bombeiros Militar de Santa Catarina }\end{array}$ & Henrique José Schueltter Nunes \\
\hline 9. & $\begin{array}{l}\text { Aplicação dos Cães de Busca e Resgate de Pessoas do } \\
\text { CBMSC nas Investigações de Incêndio }\end{array}$ & Thiago José Domingos \\
\hline 10. & $\begin{array}{l}\text { As dificuldades de implementação da atividade de cães de } \\
\text { busca e resgate pelo CBMSC }\end{array}$ & Marcelo dos Santos Pereira \\
\hline 11. & $\begin{array}{l}\text { A utilização de cães na atividade de busca e resgate no } \\
\text { CBMSC }\end{array}$ & Elcio Graciano Martins Junior \\
\hline 12. & $\begin{array}{l}\text { O uso de cães de resgate no Corpo de Bombeiros Militar } \\
\text { Santa Catarina }\end{array}$ & Marcelo Henrique Barcellos Frichs \\
\hline
\end{tabular}

Fonte: Dados de pesquisa.

O primeiro artigo a aparecer na busca realizada na Biblioteca do CBMSC é o intitulado "O emprego de cães para auxílio na detecção de acelerantes para incêndio". Nele, Borges e Vidal (2015) cogitam a utilização de cães como facilitadores na investigação de incêndio. De acordo com os autores, por sua alta capacidade olfativa, certamente o cão será capaz de facilitar o trabalho das equipes humanas frente ao sinistro ora investigado. Outrossim, eles também salientam a necessidade de testes operativos para que seja verificada por especialistas a capacidade de detecção da dupla de homem e cão (binômio), o que aumenta a credibilidade do serviço prestado (BORGES; VIDAL, 2015).

Parizotto (2013), em seu trabalho de conclusão intitulado "Parâmetros Técnicos para aprendizagem dos cães de Busca, Resgate e Salvamento", propôs um estudo para avaliar a memória de curta duração dos cães. O autor buscou novas informações que visam nortear o serviço de busca, resgate e 
salvamento com cães do Corpo de Bombeiros Militar de Santa Catarina. Após realizar diversos testes no Oeste de Santa Catarina na cidade de Xanxerê, o autor concluiu em seu trabalho que a memória de curta duração dos cães após receberem estímulos pode durar até dez minutos, o que facilitará o trabalho das equipes durante a formação de novos cães de resgate (PARIZOTTO, 2013).

No terceiro trabalho encontrado na busca, Amorim Júnior (2013) realizou sua pesquisa visando a viabilização ou não da implantação do serviço de busca, resgate e salvamento com cães no estado de Alagoas. Durante seu composto, apresentou inúmeras potencialidades do serviço de busca, resgate e salvamento com cães e, sobretudo, a grande incidência de desastres de origem natural no estado onde foi realizada a pesquisa, bem como a necessidade de apoio de outros estados que possuem o serviço de busca, resgate e salvamento com cães ativado. $O$ autor elencou qualidades fisiológicas dos cães, o que potencializa a eficiência das equipes frente a um desastre, mas também enfatizou que o serviço de busca, resgate e salvamento com cães não pode ser a única frente em uma operação, deve ser um dos "braços" do Corpo de Bombeiros Militar frente ao desastre (AMORIM JÚNIOR, 2013).

No estudo intitulado "A importância do uso de cães como ferramenta na busca de cadáveres humanos em água doce no Estado de Santa Catarina", Shiroma (2012) pesquisou sobre a importância da utilização de cães para busca subaquática em locais de água doce no estado de Santa Catarina. O autor elencou os diversos riscos que existem em uma operação de mergulho. Sendo assim, a capacidade olfativa de um cão bem treinado atenuaria o tempo resposta em uma operação de mergulho e diminuiria os riscos da operação que já não são poucos - pelo fato de o cão realizar a indicação aproximada do local onde estaria a suposta vítima. Outrossim, o autor sugere que sejam realizados estudos aprofundados sobre o objeto de pesquisa, ampliando para locais de águas rápidas, verificando a viabilidade para emprego do cão nestes 
locais (SHIROMA, 2012).

$\mathrm{Na}$ monografia apresentada por Vogel Filho (2012), é avaliada a possibilidade de inclusão dos cães como auxiliares das equipes humanas na atividade de salvamento aquático. $O$ autor citou vários países que possuem 0 serviço e correlacionou ao Corpo de Bombeiros Militar de Santa Catarina a utilização do cão também como facilitador para divulgação dos projetos institucionais para educação e prevenção em acidentes aquáticos. Por fim, o autor sugeriu novos estudos acerca deste ramo da atividade, bem como a inserção da disciplina das atividades com cães no Curso de Formação de Oficiais do Corpo de Bombeiros Militar de Santa Catarina (VOGEL FILHO, 2012).

Na monografia para conclusão do Curso de Formação de oficiais do Corpo de Bombeiros Militar de Santa Catarina, Piva (2011) descreve a importância e a necessidade de a instituição possuir cães certificados e aptos para atuarem em desastres ou em busca de pessoa perdida na mata, onde a IRO - Federação Austríaca - credenciada à ONU, certifica os cães do Corpo de Bombeiros Militar de Santa Catarina para atuação. Desta forma, também demonstra a importância de possuir em seu know-how cães com reconhecimento internacional, justificando a máxima do seu orientador, onde a vítima não pode ser a juíza da habilidade do binômio (PIVA, 2011). Já Cielusinsky (2012), em seu trabalho, ressalta a facilidade que os cães possuem para atuar em movimentos gravitacionais de terra, onde em uma operação real, combinada com outras técnicas, podem desempenhar o papel de vários homens. Também, é contemplado nesta monografia o know-how de cenários que os cães do Corpo de Bombeiros Militar de Santa Catarina podem atuar durante uma operação real seja para resgate de pessoas desaparecidas/perdidas em ambiente rural e para busca urbana (soterramento/deslizamento).

Na monografia para conclusão do curso de formação de oficiais do Corpo de Bombeiros Militar de Santa Catarina, Nunes (2015) descreve o 
modelo interno de certificação criado pela Coordenadoria de Busca, Resgate e Salvamento com cães do Corpo de Bombeiros Militar de Santa Catarina. Este modelo se pauta em regulamentos internacionais desenvolvidos pela FEMA, IRO, entre outras instituições. Também foi concluído que a certificação interna traz diversos benefícios para instituição, mas que não deve deixar de submeter seus cães para certificação de outros órgãos (NUNES, 2015).

Em seu trabalho realizado para conclusão do Curso de Formação de Oficiais do Corpo de Bombeiros Militar de Santa Catarina, Domingos (2016) explana sobre a aplicabilidade de cães que são utilizados para busca, resgate e salvamento de pessoas em prol de detecção de agentes acelerantes nas investigações de incêndio do CBMSC. Inicialmente, o autor discorre sobre sua metodologia de pesquisa, como também expõe os termos pelo qual iniciou sua pesquisa. Ao concluir sua pesquisa, o autor compara o perfil de busca nos cães com o perfil necessário para cães de detecção. Ainda, por sequente, há de se observar que cães operativos do CBMSC possuem certificação reconhecida por órgão competente, o que demonstra perfil para atividade de busca que pode ser adaptado para o serviço de investigação de incêndio. Pereira (2011) apresenta em seu composto para conclusão do Curso de Formação de Soldados uma abordagem sucinta sobre as dificuldades encontradas para formação de um binômio (dupla de homem e cão) dentro do Corpo de Bombeiros Militar de Santa Catarina. Contudo, relata sobre a então extinta $\mathrm{ABRESC}^{7}$, tempo de formação do binômio e o emprego dessa dupla em operações pela Força-Tarefa CBMSC (PEREIRA, 2011).

No artigo escrito por Martins Junior (2011) para conclusão do Curso de Formação de Soldados do Corpo de Bombeiros Militar de Santa Catarina, o autor descreve o perfil desejado para cães que, quando adultos, desempenhem atividade de busca, resgate e salvamento de pessoas desaparecidas, sejam elas em matas ou em espaço urbano (busca em escombros ou em áreas

\footnotetext{
${ }^{7}$ Associação Beneficente e Recreativa Santa Cruz.
} 
deslizadas). $\mathrm{O}$ autor apresenta também as fases necessárias para 0 condicionamento de um cão de resgate, onde a parceria, o elo entre o homem e cão, deve ser levado muito a sério nesta relação. Ainda assim, o autor apresenta a facilidade de manutenção por parte do estado para ter um cão de resgate sob sua tutela, visto o seu baixo custo para o seu alto potencial: o de localizar uma vida, considerando que uma vida não tem preço e sim valor (MARTINS JUNIOR, 2011).

No último trabalho encontrado na busca realizada na Biblioteca do CBMSC, Frichs (2011) apresenta em seu artigo para conclusão no Curso de Formação de Soldados do Corpo de Bombeiros Militar de Santa Catarina um estudo sobre o emprego de cães no CBMSC. Inicialmente, começa apresentando as vantagens sobre possuir o labrador em seu plantel, visto ser um cão robusto, flexível e de fácil manutenção por parte do condutor - infira-se um Golden Retriever em um cenário de movimento de massas. Por fim, o autor conclui que o treinamento realizado pelos militares da corporação é satisfatório para o que espera da atividade bombeiro militar (FRICHS, 2011).

\section{b. BUSCA POR "CÃES DE RESGATE" NA PLATAFORMA GOOGLE ACADÊMICO}

Na busca realizada na plataforma Google Acadêmico, ao utilizar as palavras "cães de resgate", selecionando as opções "busca avançada" e o filtro: "onde minhas palavras ocorrem do título do artigo", sem incluir as citações, apareceram seis resultados, conforme se pode visualizar na Tabela 1. Desses seis, foram separados para análise somente os que se referiam a cães de resgate pertencentes ao corpo de bombeiros ou sem denominação. Somente foi selecionado o estudo de Feitosa (2019), intitulado "Cães de Busca, Resgate e Salvamento: Uma abordagem sobre o condicionamento físico" por se tratar de um estudo de caso com cães do canil do Corpo de Bombeiros Militar do Estado do Espírito Santo, onde os cães são avaliados antes, durante 
e após os exercícios que são submetidos durante os treinamentos. Durante sua pesquisa foi constatado que cães alteram seus níveis de lactato, glicose e troponina durante e após os exercícios, e alguns se mantêm até vinte e quatro horas após o exercício realizado. Contudo, a autora chegou à conclusão de que os cães estão clinicamente adaptados à rotina de exercícios aos quais estão submetidos (FEITOSA, 2019).

\subsection{BUSCA POR SUPLEMENTAÇÃO DE CÃES NA PLATAFORMA GOOGLE ACADÊMICO}

Ao utilizar as palavras "suplementação de cães de resgate" na busca avançada e ao utilizar o filtro: "onde minhas palavras ocorrem do título do artigo" do Google Acadêmico, sem incluir as citações, apareceu um resultado. Foi analisada a dissertação intitulada "Suplementação Hidroeletrolítica e Energética sobre Parâmetros de Hidratação e Perfil Eletrolítico, Energético e Hormonal em Cães de Busca, Resgate e Salvamento", que tem por base a suplementação hidroeletrolítica de seis cães de busca, resgate e salvamento. Não foi informado de qual instituição os cães pertenciam. O estudo demonstra que a reposição energética realizada com cães que estão em treinamento/operação por via enteral, podem repor aos níveis de normalidade minutos ou horas depois de receberem estas doses energéticas. Para o Corpo de Bombeiros Militar de Santa Catarina ou para objeto deste estudo, o artigo contribui de maneira significativa, visto que a conclusão deste artigo auxiliará as equipes em campo durante a atuação frente ao desastre (CERQUEIRA, 2019).

\section{PERCEPÇÕES ACERCA dOS RESULTADOS}

Para condicionar um cão fisicamente, conforme Case, Carey e Hirakawa (1998) discorrem em seus artigos, deve se levar em conta os níveis de 
atividade física realizado por um cão, sua constituição corporal, clima, idade, sexo, entre outros fatores que devem ser respeitados em um cão. Neste artigo, o objeto de estudo são os cães da raça labrador, conforme contextualizado possuem propensão a desenvolver a patologia conhecida como displasia coxofemoral, onde o cão tem um ângulo maior de abertura do encaixe entre 0 acetábulo e a cabeça do fêmur. Já Prestes (2009) cita em seu artigo que cães foram utilizados desde a segunda guerra mundial para apoio a equipes humanas, mas qual o critério para inclusão desses cães no plantel dos Corpos de Bombeiros Militar? Na Diretriz Operacional número dez do Corpo de Bombeiros Militar de Santa Catarina, qual versa e regula sobre o Serviço de Busca e Resgate com Cães, dispõe que, para inclusão no plantel do Corpo de Bombeiros Militar de Santa Catarina, o cão deverá atender os requisitos mínimos exigidos pela câmara técnica veterinária da Coordenadoria de Busca, Resgate e Salvamento com Cães do CBMSC. Após isso, o cão deverá ser submetido a check-up periódicos garantindo a salubridade dos cães. Outrora, anualmente (até os dois anos de idade), os cães deverão realizar exames para verificação de displasia coxofemoral, hemograma completo, exames para verificação da função renal e hepática, com isso existe a garantia da redução que estas patologias se instalem no plantel do Corpo de Bombeiros Militar de Santa Catarina.

O serviço de cinotecnia é um dos serviços especializados do Corpo de Bombeiros Militar de Santa Catarina, tanto que há reconhecimento internacional por parte de entidades ligadas a ONU, isso pode ser comprovado ao acessar o site da Internacional Rescue Dog Organisation - IRO, no link onde direciona para as entidades reconhecidas credenciadas, e no Brasil o Corpo de Bombeiros Militar de Santa Catarina é a única instituição reconhecida. Nada obstante, Nunes (2015) defende o modelo de certificação interna, o que tornaria o Corpo de Bombeiros Militar de Santa Catarina mais autônomo em relação à IRO por possuir certificação própria, com militares capacitados a realizar a arbitragem. Da mesma forma, cita que as certificações com 
reconhecimento internacional promovidas em parceria entre o CBMSC e a IRO não devem substituir a certificação Internacional. Contudo, a certificação estadual/nacional, acontecerá nos moldes da certificação internacional, mantendo o padrão exigido em uma certificação internacional e diminuindo os custos que gera uma prova de certificação internacional, podendo ser promovidas várias provas no decorrer do ano.

No estudo desenvolvido por Feitosa (2019) cães do canil do Corpo de Bombeiros Militar do Espírito Santo têm os seus níveis de lactato, glicose e troponina quando são submetidos aos exercícios físicos realizados durante o treinamento e posteriormente retornam a sua normalidade, porém o artigo da autora é vago por não explicar de qual maneira isso ocorrere, tampouco se exige suplementação ou reposição hidro ou eletrolítica. Já na dissertação escrita por Cerqueira (2019), foi realizado estudo em seis cães, de qual corporação não foi descrito, relata sobre a reposição hidroeletrolítica em cães que exercem atividades de alto rendimento, a atividade de busca, resgate e salvamento. $O$ estudo sugere que durante a atividade de busca, resgate e salvamento seja proporcionado a este cão por via enteral a reposição hidroeletrolítica, para manutenção do cão na operação.

\section{CONCLUSÃO}

Conforme pesquisado para o referido artigo, o autor chegou à conclusão que as literaturas existentes são insuficientes para embasar o conhecimento científico do bombeiro militar que atua na função de condutor na atividade de busca, resgate e salvamento com cães. $O$ autor do presente artigo, é bombeiro militar e atuou no desastre ocorrido na cidade de Brumadinho, no estado de Minas Gerais, no rompimento da Barragem I do complexo de minas do Córrego do Feijão. Durante a atuação, percebeu a discrepância no condicionamento físico dos cães de busca, resgate e salvamento, o que o instigou a pesquisar sobre o referido assunto. Conforme 
descrito no início deste artigo, parte deste composto é baseado no conhecimento empírico analítico e práticas visando o conhecimento do cão Orion que, conduzido pelo autor deste artigo, pautou-se no condicionamento físico semelhante ao que é realizado com cães de trenó. Treinos de alta intensidade, longa duração, de força, força e aeróbicos combinados, foram realizados com o cão supracitado. Infelizmente, por questões pandêmicas, não foi possível valorar os dados clínicos devido ao fechamento do Hospital Veterinário da Universidade do Estado de Santa Catarina - UDESC campus de Lages.

Por essas razões, são deixadas, a partir dessas reflexões, sugestões para que seja realizado um estudo aprofundado e direcionado para o condicionamento específico de cães de Busca, Resgate e Salvamento, visto - pouco conteúdo produzido nesta área de conhecimento. Cães que desempenham essa atividade, necessitam possuir alto condicionamento físico e devem estar sempre em condições plenas pois, a qualquer momento, estarão em busca de uma vida, e a vida de uma vítima não pode estar à sorte de um cão preparado ou não, afinal, possuímos certificação internacional, nacional e estadual, para que vítimas não sejam juízes da habilidade do binômio.

\section{REFERÊNCIAS}

AMORIM JÚNIOR, R. W. A implementação do serviço de busca, resgate e salvamento com cães no estado de alagoas. Biblioteca CBMSC, 2013. Disponível em: https://biblioteca.cbm.sc.gov.br/biblioteca/index.php/component/docman/doc_d ownload/386-roberto-wanderley-amorim-junior Acesso: 22/02/2021.

BORGES, J. L.; VIDAL, V. V. O emprego de cães para auxílio na detecção de acelerantes de incêndio. Biblioteca CBMSC, 2013. Disponível em: https://biblioteca.cbm.sc.gov.br/biblioteca/index.php/component/docman/doc_d ownload/939-jihorgenes-luciano-borges- Acesso: 22/02/2021. 
Revista Científica do Corpo de Bombeiros Militar de Pernambuco

Artigo Publicado no Vol.07 N.20 - Edição Especial 2021 - ISSN 2359-4829

Versão on-line disponível em: http://www.revistaflammae.com

CASE, L. P.; CAREY, D. P.; HIRAKAWA, D. A. Nutrição canina e felina. Madrid: Harcourt Brace de España S. A., 1998.

CIELUSINSKY, A. D. Emprego de cães nas operações de busca em ocorrências de movimentos gravitacionais de terra. Biblioteca CBMSC, 2012. Disponível em:

https://biblioteca.cbm.sc.gov.br/biblioteca/index.php/component/docman/doc_d ownload/292-alan-delei-cielusinsky Acesso: 22/02/2021.

DOMINGOS, T. J. Aplicação dos cães de busca e resgate de pessoas do CBMSC nas investigações de incêndio. Biblioteca CBMSC, 2016. Disponível em:

https://biblioteca.cbm.sc.gov.br/biblioteca/index.php/component/docman/doc_d ownload/558-tiago-jose-domingos Acesso: 22/02/2021.

EBERLE L. B. C.; SILVA, R. M.; MONTEIRO, V. L.; MOURA, R. A. Estudo sobre o uso de tecnologias da IOT associadas aos cães em operações de busca e resgate. Disponível em:

https://publicacao.cimatech.com.br/index.php/cimatech/article/view/190/73 Acesso: 22/01/2021.

FRICHS, M. H. B. O uso de cães de resgate no Corpo de Bombeiros Militar Santa Catarina. Biblioteca CBMSC, 2011. Disponível em: https://biblioteca.cbm.sc.gov.br/biblioteca/index.php/component/docman/doc_d ownload/185-henrique-barcellos-frichs- Acesso em: 22/02/2021.

MARTINS JUNIOR, E. G. A utilização de cães na atividade de busca e resgate no CBMSC. Biblioteca CBMSC, 2011. Disponível em:

https://biblioteca.cbm.sc.gov.br/biblioteca/index.php/component/docman/doc_d ownload/204-elcio-graciano-martins-junior- Acesso em: 22/02/2021.

NUNES, H. J. S. Certificação de cães de busca, resgate e salvamento: análise sobre a eficácia da metodologia de avaliação adotada. Biblioteca CBMSC, 2015. Disponível em:

https://biblioteca.cbm.sc.gov.br/biblioteca/index.php/component/docman/doc_d ownload/546-henrique-jose-schuelter-nunes Acesso: 22/02/2021.

PARIZOTTO, W. Parâmetros técnicos para a aprendizagem dos cães de busca, resgate e salvamento. Biblioteca CBMSC, 2013. Disponível em: https://biblioteca.cbm.sc.gov.br/biblioteca/index.php/component/docman/doc_d ownload/385-walter-parizotto- Acesso: 22/02/2021.

PARIZOTTO, W. . A arte de ensinar seu cachorro. 1. ed. São Paulo: Delicatta, 2019. v. 1. 142p . 
PARIZOTTO, W. ; NETTO, S. O. ; CATTONI, M. P. . Rastreamento humnao e rastreamento com o emprego de cães - Proposta de doutrina conjunta. 1. ed. Joinville: Marumby, 2018. v. 1. 90p .

PEREIRA, M. dos S. As dificuldades de implementação da atividade de cães de busca e resgate pelo CBMSC. Biblioteca CBMSC, 2011. Disponível: https://biblioteca.cbm.sc.gov.br/biblioteca/index.php/component/docman/doc_d ownload/212-marcelo-dos-santos-pereira- Acesso: 22/02/2021.

PIVA, I. M. A certificação dos cães de busca e resgate do Corpo de Bombeiros Militar de Santa Catarina. Biblioteca CBMSC, 2011. Disponível em:

https://biblioteca.cbm.sc.gov.br/biblioteca/index.php/component/docman/doc_d ownload/103-ismael-mateus-piva- Acesso: 22/02/2021.

PRESTES, S. Utilização de cães pelo corpo de bombeiros da Polícia Militar do Paraná em operações de busca terrestre. Curitiba, 2009. Disponível em:

https://acervodigital.ufpr.br/bitstream/handle/1884/66818/SAMUEL\%20PRESTE S.pdf?sequence=1\&isAllowed=y Acesso: 22/02/2021 .

SHIROMA, V. H. A importância do uso de cães como ferramenta na busca de cadáveres humanos em água doce no estado de Santa Catarina. Biblioteca CBMSC, 2012. Disponível em:

https://biblioteca.cbm.sc.gov.br/biblioteca/index.php/component/docman/doc_d ownload/276-victor-heidy-shiroma- Acesso: 22/02/2021.

VOGEL FILHO, A. R. Um estudo sobre as possibilidades de uso de cães nas atividades de salvamento aquático pelo Corpo de Bombeiros Militar de Santa Catarina. Biblioteca CBMSC, 2012. Disponível em: https://biblioteca.cbm.sc.gov.br/biblioteca/index.php/component/docman/doc d ownload/250-arthur-roberto-vogel-filho- Acesso: 22/02/2021. 